Itinerarius

Peflectionis

Revista Eletrônica de Educação do Curso de Pedagogia

do Campus Avançado de Jataí da Universidade Federal de Goiás

[Vol I - n.2 ] [jan/jul] [ 2006 ]

ISSN: $1807-9342$

\title{
A CONCEPÇÃO PEDAGÓGICA EM ROUSSEAU
}

PAMPLONA, Renata Silva (UFG/CAJ).repamplo@brturbo.com.br

Abstract: Through this article we intend to discuss the pedagogical conception proposed by the French philosopher Jean Jacques Rousseau, a precursor in thinking a child as an individual, creative and autonomous.By arguing that students play an important and central role in the educacional process, no longer passive, it becomes essential to review his conception, especially when his theory claims to be necessary a diferentiated educational posture that gives privilege to the student's reflexive knowledge. We also intend to go along the particular manner that Rousseau deals with the person's formation, considering it as innate to human condition, which means that his ideas are entailed to the defense of freedom, naturalness and negativity, to propose a model of education that truly forms a person prepared to real life, in order to accommodate his primary necessities and, by consequence, their social needs. Rousseau's way manner of versing about these themes allows the seek of a new form of comprehension or a new glance in postures often stereotyped and radicated in pedagogical pactices that might not attend the primary goal of the person's formation. Thus, the proposal of this article is to go along Rousseau's thought, seeking to reflect about it and absorb his contributions to a critical pedagogical practice as well as to a theoretical concept.

Key-words:Jean-Jacques Rousseau - pedagogical conceptions

Resumo: Este artigo busca refletir sobre a concepção pedagógica do filósofo Jean-Jacques Rousseau, que por ser um dos pioneiros em pensar a criança como ser singular, criativo e autônomo, e por pensar o aluno como centro no processo educacional, e não mais como um ser passivo, torna-se indispensável rever sua concepção, sobretudo quando se dispõe pensar uma postura educacional diferenciada e que privilegie o saber reflexivo do aluno. Busca-se discorrer sobre a particular maneira como Rousseau pensa a formação do homem, considerando-a como parte intrínseca da condição humana, sendo assim, suas idéias estarão vinculadas à defesa da liberdade, naturalidade e negatividade, para propor uma educação que possa verdadeiramente formar um homem para a vida, para atender as suas necessidades primeiras de ser homem, e conseqüentemente as sociais. A maneira rousseauniana de versar sobre essa temática permite a 
busca de uma nova compreensão, ou um novo olhar sobre posturas muitas vezes estereotipadas, arraigadas em práticas pedagógicas que podem não mais atender ao objetivo primeiro que é a formação humana. Para tanto a proposta desse trabalho é percorrer o pensamento rousseauniano, buscando refleti-lo e absorver suas contribuições para a prática pedagógica, e concepção teórica. Palavras chaves: Jean-Jacques Rousseau-Concepção pedagógica.

\section{Introdução}

Este artigo faz parte de uma pesquisa teórica (monografia) de conclusão de especialização em Educação Infantil, cuja temática geral baseia na compreensão do conceito de infância em Rousseau, (PAMPLONA, 2005). Optou-se aqui em discorrer sobre a segunda parte desse trabalho que reflete a concepção pedagógica em Rousseau. Inicialmente é retomada brevemente a origem da relação concepção pedagógica e política, posteriormente realiza-se um resgate histórico, a época do pensador até se chegar à reflexão das idéias do filósofo acerca do entendimento do processo educacional. A análise se conclui no questionamento da postura pedagógica dos educadores que atuam com crianças, em especial no âmbito da educação infantil.

\section{A concepção pedagógica em Rousseau}

Antes de embrenhar-se na concepção rousseauniana, faz-se necessário esclarecer que as obras Discurso sobre a origem da desigualdade entre os homens, Do contrato social, ambas sobre política, e Emílio ou Da educação, são complementares, já que o pensamento pedagógico de Rousseau não se separa da concepção política; isto se comprova pelo fato de suas obras Emílio e Do contrato social terem sido publicadas juntas. Segundo Rousseau, "É preciso estudar a sociedade pelos os homens e os homens pela sociedade; quem quiser tratar separadamente a política e a moral nada entenderá de nenhuma das duas" (ROUSSEAU, 1995, p. 309). A relação estabelecida entre política-educação é fundamental para se entender de onde surgem às idéias de Rousseau e em que contexto.

O séc XVIII, Século das Luzes, é marcado por grandes transformações que abalam a Europa: a Revolução Industrial, que altera o panorama socioeconômico com a mecanização da indústria e a Revolução Francesa, que condena os privilégios hereditários da nobreza, sendo que, a burguesia defende a igualdade de direitos e oportunidades. Neste contexto surge o iluminismo, caracterizado pela capacidade da razão humana de interpretar e reorganizar o mundo, de não mais 
itinerarius

Teflectionis

Revista Eletrônica de Educação do Curso de Pedagogia do Campus Avançado de Jataí da Universidade Federal de Goiás [Vol I - n.2 ] [jan/jul] [ 2006 ]

ISSN: $1807-9342$

aceitar o teocentrismo medieval que já vinha sendo condenado desde o Renascimento. Os dogmas e fanatismos são questionados e objetiva-se a libertação do domínio do terrorismo sobrenatural. O iluminismo tinha profunda convicção na razão do indivíduo em sua moral, independência e liberdade intelectual, na justiça do Estado, na ação política livre, no respeito das crenças religiosas, na defesa dos direitos dos homens. No entanto, esse período também foi marcado por suas contradições, em especial quando acreditava que as classes humildes não estavam em condições de serem educadas; dessa forma se pode notar o elitismo da educação que queria substituir a velha aristocracia de família, de posição e da igreja pela nova aristocracia de riqueza e inteligência. Rousseau vem justamente contrapor essas contradições e para isso propõe a fase naturalista do movimento do século XVIII, pensando o homem como ser ingênuo, puro, traçando um novo ideal para a sociedade.

O liberalismo representa as aspirações da burguesia desejosa de gerenciar seus negócios. As idéias liberais se opõem ao absolutismo, defendem a propriedade privada como direito natural, como direito à vida, a liberdade e aos bens necessários para a conservação de status e poder, sendo esses bens conseguidos por meio do trabalho, os que não conseguem é porque não se empenharam, ficando a burguesia assim legitimada e superior perante a realeza e a nobreza e perante aos pobres.

Nesse período conturbado, cheio de rompimentos com o mundo velho surgem reflexões políticas e pedagógicas representadas, dentre outros, pelos filósofos Voltaire, D' Alembert, Diderot, Kant, e Rousseau. Segundo Assmann "Rousseau não apenas luta pela separação de um homem e mundo velho, preconizando a revolução de 1789, mas também anuncia o beco sem saída do modelo burguês" (ASSMANN: 2004). O que mostra que para Rousseau o que importa é pensar o homem integral, o que faz dele um ser, e um ser bom, e não apenas entendê-lo dentro de uma transformação social e política que contribui para o desenvolvimento social. Para Palácios (1997), Rousseau não é nem racionalista nem iluminista, uma vez que seu estudo é o da essência humana, que está em constante transformação, que se altera por causas externas e históricas. O próprio Rousseau afirma no Emilio, "Nosso verdadeiro estudo é o da condição humana" (ROUSSEAU, 1995, p. 14).

É nesse contexto histórico geral em que a razão não se aquieta diante das dúvidas, que se deve procurar entender a concepção rousseauniana. Mas, não somente por meio do primado da razão, mas principalmente pela emoção. Rousseau rompe com a hegemonia racionalista, objetiva 
itinerarius

Teflectionis

Revista Eletrônica de Educação do Curso de Pedagogia do Campus Avançado de Jataí da Universidade Federal de Goiás [Vol I - n.2 ] [jan/jul] [ 2006 ]

ISSN: $1807-9342$

e faz uso da subjetividade, do sentimento, do desejo, das vontades. Ele condena a educação proposta e critica a forma como a criança é vista e tratada, assim como o descaso pelo espaço da infância ou pelo não reconhecimento desse espaço.

Partindo então desse enfoque questionador e subjetivo, Rousseau compreenderá que a criança não pode estar passiva às determinações do mundo adulto e da sociedade em que vive e defenderá como eixo central na educação da criança, a sua liberdade. A educação de Emílio terá um só objetivo que é formar um homem livre, capaz de se defender contra todos os constrangimentos e para isso Rousseau afirma que há apenas um meio, que é tratá-lo como um ser livre, não de forma romanceada como hoje se faz uso corrente, mas de forma profunda, complexa. A liberdade será na concepção rousseaniana o fundamento que a faz, que a conduz, o que faz dela um diferencial para as idéias propostas em sua época. Como afirma Rousseau "O homem verdadeiramente livre só quer o que pode e faz o que lhe agrada. Eis a minha máxima fundamental. Trata-se apenas de aplicá-la à infância, e todas as regras da educação decorrerão dela”. (ROUSSEAU, 1995, p. 76).

Empreender-se na busca do entendimento da concepção rousseauniana é antes entender a proposta central de deixar a criança livre, é compreender que essa liberdade é intrínseca à criança e assim deve ser reflexiva. Não fazer tal reflexão seria cometer o erro de não entendê-la da maneira pensada originalmente. Rousseau não defende que o Emílio, viva em meio natural, no campo, somente pelos benefícios óbvios que é se criar numa atmosfera saudável, tampouco admite o espontaneísmo para que Emilio profira palavras inúteis, quando assim o desejar. Segundo ele "No estado agora que as coisas estão, um homem abandonado a si mesmo desde o nascimento entre os outros seria o mais desfigurado de todos". (ROUSSEAU, 1995, p. 7). Emílio será livre, não desamparado. Ao contrário, terá constantemente um olhar de proteção sobre o seu.

Neste sentido pode se afirmar que a questão da liberdade não pode ser compreendida pela razão puramente epistemológica e sim filosófica, que interrogue o verdadeiro sentido atribuído aessa liberdade, a fim de que mantenha uma flexibilidade diante das reflexões, exemplos práticos, devaneios e dúvidas de Rousseau. A concepção rousseauniana deve ser pensada a partir desse aspecto.

Seria tentador, simples e rápido afirmar que esta concepção é a pedagogia naturalista, espontaneísta, que pretende educar o homem longe das civilizações, isolado nas florestas, impedindo-o de corromper-se com os vícios da sociedade, no entanto, ela é muito mais ampla, a 
Linerarius

Teflectionis

Revista Eletrônica de Educação do Curso de Pedagogia do Campus Avançado de Jataí da Universidade Federal de Goiás [Vol I - n.2 ] [jan/jul] [ 2006 ]

ISSN: $1807-9342$

ponto de se afirmar que não existe uma pedagogia rousseauniana no sentido sistemático e classificatório, por isso, talvez empregar tal termo seja um erro. Rousseau, desde o prefácio do Emilio, ou Da Educação, previne os leitores sobre esse aspecto.

No que diz respeito ao que chamaremos a parte sistemática, que aqui não é senão a marcha da natureza, é ela que mais desconcertará o leitor; será também por aí, sem dúvida, que me atacarão, e talvez com alguma razão. Acreditarão estar lendo menos um tratado de educação do que os devaneios de um visionário sobre a educação (ROUSSEAU, 1995, p. 4).

O aspecto natural abordado deve ser pensado em partes. Segundo Rousseau, o homem é moldado pela educação, sendo que essa vem da natureza ou dos homens ou das coisas. A educação da natureza não depende dos homens; a das coisas, só em alguns aspectos, a dos homens é a única que se pode atuar. E é por meio dessa atuação que para Rousseau pode-se fazer algo pela educação da criança ou impedir que ela seja apenas parte de um corpo social desprovida de sua essência. O filósofo interrogando a si mesmo, questiona: "para formar um homem raro, o que temos de fazer? Muito, sem duvida impedir que algo seja feito" (ROUSSEAU, 1995, p. 13). Por isso a concepção rousseauniana será a de uma educação natural e negativa, já que para o autor na ordem natural, os homens são todos iguais e sua vocação primeira são ser homens, viver será o ofício de Emílio; e negativa, que consiste em não sobrepor a criança com ensinamentos que ela ainda não está em condições de entender, seja pela razão prática ou pela moral. Para ele, seria necessário que a alma da criança fosse protegida enquanto não estivesse formada por suas faculdades.

Seria preciso que nada fizessem de sua alma, até que ela estivesse de posse de todas as suas faculdades, pois é impossível ela perceber a chama que lhe mostrais enquanto é cega, e seguir, em meio à imensa planície das idéias, uma estrada que a razão traça ainda tão levemente para os melhores olhos.

Portanto, a primeira educação deve ser puramente negativa. Consiste, não em ensinar a virtude ou a verdade, mas em proteger o coração contra o vício e o espírito contra o erro (ROUSSEAU, 1995, p. 91)

A única ciência proposta a ensinar é a dos deveres do homem, mas esses deveres devem ser encontrados pelas crianças e não condicionados a elas, pois como salienta Rousseau, a experiência antecipa as lições, é através do agir que a criança manipula e apreende o real, se torna senhora dele. Ele aprofunda a sua crítica afirmando não dever dar lições sobre a idéia de moral ou sobre as relações sociais, já que a criança não se encontra na idade da razão e ainda não possui 
condições de compreender o que venha a ser essas idéias. Insistir nelas seria correr o risco de que elas fossem entendidas de forma falsa e não mais poderiam ser desfeitas. A concepção rousseaniana defende que a criança seja preservada o máximo de tempo que for possível. Ela não deve saber o que é a mentira, para que não minta, o enganar, para que não engane; o compromisso, para que não o desfaça, a caridade, se não possui condições afetivas e efetivas de entendê-la e praticá-la. Os ensinamentos de virtudes devem ser evitados, para que não despertem os vícios, pois uma vez ensinado o que é bom, ensina-se o que é ruim, o que é mau. A criança deve ser preservada em sua ingenuidade para que viva de acordo com sua natureza e para que se torne um homem de bem.

Lembrai-vos de que, antes de ousar empreender a formação de um homem, é preciso terse feito homem; é preciso ter em si o exemplo que se deve propor. Enquanto a criança ainda não tem conhecimento, temos o tempo de preparar tudo que a rodeia para só impressionar seus primeiros olhares com objetos que lhe convém ver (ROUSSEAU, 1995, p. 93).

Isto não significa também que a criança deva ser tratada como se fosse sempre uma completa inábil em tudo e em todos os momentos, mas o oposto. Já que se espera que a mesma aprenda com a vida e vivendo, nada mais natural do que esperar que essa criança dê respostas de aprendizado constantemente. Visto dessa maneira, Rousseau critica a educação daqueles que tentam disfarçar o óbvio para a criança, tentando encobrir situações, assuntos, fatos que julgam impróprios para as mesmas, de forma que mais fazem atrair sua atenção do que desviá-la, reforçando positivamente, ou seja, para que o interesse pelo mesmo assunto ressurja sucessivamente. Para a filosofia rousseauniana a educação não deve se adiantar à criança tampouco se atrasar da mesma.

As crianças têm uma sagacidade singular para reparar através de todos os disfarces da decência os maus costumes que ela encobre. A linguagem depurada que lhes é ditada, as aulas de decência que lhes são dadas, o véu de mistério que se tenta estender diante de seus olhos são tantos outros aguilhões para a sua curiosidade. Pela maneira com que o fazem, é claro que aquilo que se finge esconder-lhes é para lhes ser ensinado, e essa é, dentre todas as aulas que lhes são dadas, aquela de que tiram maior proveito (ROUSSEAU, 1995, p. 278).

A concepção rousseauniana não se preocupa em preparar a criança, para a vida, mas, para que viva o hoje, para que saiba sentir a vida no cotidiano, saiba amar e respeitar o outro de forma natural, como se isso fosse inerente a ela. O que pensar então dessa concepção no nosso momento 
atual e não preocupar com a preparação das crianças numa sociedade em que a competição é mola sustentadora da sobrevivência? Como preservar as crianças numa sociedade civil que as corrompe ainda na barriga de suas mães, por meio de um mercado industrial avassalador, que faz delas objeto de ascensão constante?

\begin{abstract}
As imagens de infância são obscurecidas por uma adultização precoce que institui modos de ser através da textualidade presente na marca apresentada pelas campanhas publicitárias, configurando representações, pois "as imagens que o mundo, principalmente social, nos apresentam, a rigor, não nos apresenta isentamente, é através do olhar que botamos sobre as coisas que, de certa maneira, as constitui" (Veiga - Neto, 199 p. 27). A partir da constituição das "coisas" e significação dos elementos lingüísticos e visuais que compõem o texto publicitário, formas de interpelar os sujeitos em desenvolvimento vão sendo instituídas em um processo enunciador, regulador e produtor de significados a partir de seus diferentes discursos (CARVALHO, 2005, p. 01)
\end{abstract}

Para Rousseau, pensar essas questões como barreira, seria o mesmo que aceitar passivamente a ordem proposta, sem que nada fosse capaz de fazer. O entendimento aqui realizado sobre a concepção rousseauniana visa compreender e buscar pensá-la dentro de suas especificidades e pormenores da prática pedagógica, que passam muitas vezes despercebidos; alguns críticos podem com alguma razão dizer que a proposta feita por Rousseau é grandiosa, mas difícil de ser aplicada.

Sobre essas considerações pode-se ponderar sobre dois pontos: primeiro, já foi considerado o fato de que Rousseau não escreve um tratado de educação. Assim sendo não há razões para se querer uma "aplicação" de sua teoria. O próprio Rousseau afirmou no Emílio, ou Da Educação (livro II), saber dessa dificuldade. A criança está submetida às constituições sociais e não há como isolá-la de todo o convívio, uma vez que elas nascem numa sociedade e convivem com as imperfeições, contradições, corrupções dos homens dessa sociedade. Ele ressalta que em nenhum momento afirmou ser fácil educar as crianças de forma natural, mas que se deve tentar realizar essa educação e o máximo que se conseguisse aproximar dessa educação natural e livre já seria vitoriosa a tentativa.

É nessa perspectiva de otimismo que se busca aqui compreender a concepção rousseauniana, como uma mãe e um pai que educa o seu filho, na certeza de que não será capaz de preservá-lo de todo o mal do mundo, nem mesmo de lhe oferecer tudo o que há de melhor, mas de que mesmo assim, tentará, dando o seu melhor, para que este seja o melhor para si e para os outros. 
Mas onde colocaremos essa criança para assim educa-la como um ser insensível, como um autômato? Guarda-la-emos no globo lunar, numa ilha deserta? Afasta-la-emos de todos os humanos? (...) Mostro o alvo que devemos propor-nos; não digo que possamos alcança-lo, mas sim que aquele que mais se aproximar dele será o mais bem-sucedido (ROUSSEAU, 1995, p. 93).

Não se trata de deixar as crianças em uma redoma de vidro, mas de preservá-las em sua infância, de respeitá-las enquanto crianças, de apoiá-las em suas necessidades e de educá-las para que possam viver em sociedade, mas principalmente viver para si, respeitando o seu eu. Esse será o mote para a educação rousseauniana.

Pretendendo uma educação natural e livre, o primeiro favorecido deve ser o indivíduo enquanto sujeito singular e não o mesmo dentro de um corpo social, já que este retiraria dele a possibilidade de ser esse homem autêntico, pois quando se educa uma criança pensando no que ela pode vir a ser, na verdade esse pensamento está vinculado ao que ela possa vir a ser e ter dentro dos conceitos sociais. Por essa razão Rousseau diz ser necessário optar entre se fazer um homem ou um cidadão, dessa forma é visível a compreensão do sentido da naturalidade e subjetividade na concepção pedagógica rousseauniana.

\begin{abstract}
O homem natural é tudo para si mesmo; é a unidade numérica, o inteiro absoluto, que só se relaciona consigo mesmo ou com seu semelhante. O homem civil é apenas uma unidade fracionária que se liga ao denominador, e cujo valor está em sua relação com o todo, que é corpo social. As boas instituições sociais são as que melhor sabem desnaturar o homem, retirar-lhe sua existência absoluta para dar lhe uma relativa, e transferir o eu para a unidade comum, de sorte que cada particular não se julgue mais como tal, e sim como uma parte da unidade, e só seja perceptível no todo (ROUSSEAU, 1995, p. 11)
\end{abstract}

Para Rousseau a formação educacional do homem deve acontecer desde o seu nascimento até a idade adulta, sem que nada nesse percurso passe desapercebido aos olhos daquele que se destina a cuidar da formação de uma criança, de forma a guiar todos os passos da mesma. No caso de Emílio, ele educa-o de forma livre. Emílio, ou Da Educação é uma ficção romanceada que se assemelha às obras de arte, o que torna visível que para falar da educação de uma criança Rousseau faz arte por meio das palavras. Para Rousseau a educação é uma arte e, como tal, é impossível de se obter sucesso pleno, já que a mesma não depende de ninguém, assim como a obra de arte não depende exclusivamente de seu autor, mas de todo o universo que a faz. Coli (1995) descreve sobre este assunto dizendo que "o conjunto da obras faz pensar numa grande geleira: aparentemente imutável, ela se desloca, no entanto, possui contínuos movimentos interiores. É impossível domesticar a geleira" (p.86). Também assim é a educação, não depende 
exclusivamente do educador, mas de todo o contexto educacional. Todos os agentes evolvidos, aluno, professor, sociedade, e todas as esferas física e material devem se atrelar a fim de que a educação se torne naturalmente possível.

Ao levantar essa temática possibilidade-impossibilidade, percebe-se mais um dos paradoxos de Rousseau. Por um lado ele questiona a impossibilidade da educação, mas ao mesmo tempo, afirma que o homem é moldado pela mesma, assim como as plantas são estruturadas pela cultura, assim devem ser os homens pela educação. "Tudo o que não temos ao nascer e de que precisamos quando grandes nos é dado pela educação" (ROUSSEAU, 1995, p. 8). A educação precisa acontecer, de forma natural, respeitando cada momento de crescimento da criança e tudo o que a compõe, como tentativas, erros, acertos, frustrações, vitórias, realizações, dúvidas, expectativas, certezas, enfim, tudo o que permita um crescimento que advenha da criança e não que seja posto, inculcado na mesma. Assim como uma obra de arte, a educação deve fruir por si. Deve ser possível olhar para a obra de arte e reconhecê-la, assim como para o indivíduo bem formado e reconhecer uma nobre educação. Por isso ele defende que embora Emílio seja educado no campo ele será capaz de, melhor que outros, se portar em qualquer lugar que se encontre.

\begin{abstract}
Emílio não foi feito para permanecer sempre solitário; membro da sociedade, deve cumprir seus deveres. Feito para viver com os homens, deve conhecê-los. (...) suas paixões poderão iludi-lo, sem dúvida; quando é que não iludem os que se entregam a elas? Mas pelo menos não será enganado pelas paixões dos outros. Se as vir, vê-las-á com os olhos do sábio, sem ser arrastado por seus exemplos nem seduzido por seus preconceitos.Assim como há uma idade própria para o estudo das ciências, também há uma para bem compreender os costumes do mundo (ROUSSEAU, 1995, p. 449-450).
\end{abstract}

Todos esses aspectos da concepção pedagógica abordada por Rousseau despertam os educadores para o atual cenário educacional e em particular para a educação infantil, onde as crianças são muitas vezes renegadas, desamparadas, violentadas em seus direitos, negligenciadas perante suas necessidades. Rousseau enumera pontos consideráveis na prática dos pais e educadores para com as crianças; critica e desperta a atenção para posturas que preservem a criança em sua fase de criança.

\title{
Referências Bibliográficas
}

ASSMANN, Selvino José. Sobre a política e a pedagogia em Rousseau: É possível ser homem e ser cidadão? Santa Catarina: UFSC, 2004. Disponível em: $<$ http://www.cfh.ufsc.br/ wfil/selvino2.htm $>$ Acesso em: 20 jul. 2004. 
Revista Eletrônica de Educação do Curso de Pedagogia do Campus Avançado de Jataí da Universidade Federal de Goiás [Vol I - n.2 ] [jan/jul] [ 2006 ]

ISSN: $1807-9342$

CARVALHO, Rodrigo Saballa de. As marcas do invisível - Propaganda, Infância e Produção de Identidades. Porto Alegre: UFRGS. Disponível em: $<$ http://www.conteudoescola.com.br/site/content/view/139/31/1/4/ >Acesso em: 28 mai. 2005.

COLI, Jorge. O que é arte. São Paulo: Brasiliense, 2000 (Coleção primeiros passos).

PALÁCIOS, Gonçalo Armijos. Locke e Rousseau: Antecedentes Teóricos do Marxismo. In: BRITO, Adriano Naves, HECK, José N.(orgs). Ética e Política Goiânia: UFG, 1997.

ROUSSEAU, Jean-Jacques. Emílio ou Da educação. São Paulo: Martins Fontes, 1995. 